\title{
MS15-P16 | OXIDES UNDER EXTREME CONDITIONS: PUSHING THE LIMITS OF NEUTRON
}

\section{DIFFRACTION}

Capone, Mara ( ISIS STFC, University of Edinburgh, ESS, Didcot, GBR); Ridley, Christopher (ISIS STFC, Didcot, GBR); Funnell, Nicholas (ISIS STFC, Didcot, GBR); Loveday, John (University of Edinburgh, Edinburgh, AUT); Guthrie, Malcolm (European Spallation Soruce, Lund, SWE); Bull, Craig (ISIS STFC, Didcot, GBR)

The $\mathrm{LaCo}_{x} \mathrm{Mn}_{1-\mathrm{x}} \mathrm{O}_{3}$ perovskite series has been widley studied as responses to chemical composition or volume give rise to a variety of electrical and magnetic properties [1]. Volume changes can be induced by the application of pressure, which can be used to study structural-property relationships. High-pressure neutron-diffraction experiments have been performed on $\mathrm{LaCO}_{0.9} \mathrm{Mn}_{0.1} \mathrm{O}_{3}$ and $\mathrm{LaCoO}_{3}$ powders. Neutron powder diffraction is essential to determine the structure of perovskite-like oxides. The high-pressure structural evolution of $\mathrm{LaCO}_{0.9} \mathrm{Mn}_{0.1} \mathrm{O}_{3}$ will be presented [2]. The change in tilting angle and strain has been determined upon pressure. This study compliments high-pressure magnetisation measurements, where the Curie temperature shows a strong dependence on applied pressure. A structural study of $\mathrm{LaCoO}_{3}$ as a function of pressure and temperature using neutron diffraction will also be presented [3]. This study is of great interest for its unique temperature-dependent electronic properties. Tha aformentioned experiments have been carried out on the PEARL instrument, the highpressure-dedicated diffractometer at ISIS, STFC [4]. We are developing new pressure cells for neutron diffraction to extend the maximum achievable pressure at ISIS.

[1] C. Autret et al, 2005, J. Phys, Condens. Matter 17, 1601;

[2] C. Capone et al, 2018, J. Phys. Condens. Matter 30, 035402;

[3] M. Capone et al, 2019, Physica Status Solidi A, 1800736;

[4] C. Bull et al, 2016, High Press. Res. 36, 493. 